Give and Take? Knowledge Exchange between Older and Younger Employees as a

Function of Generativity and Development Striving

\author{
Ulrike Fasbender \\ Justus-Liebig-University Giessen \\ Fabiola H. Gerpott \\ WHU - Otto Beisheim School of Management \& ARC Centre of Excellence in Population \\ Ageing Research (CEPAR) \\ Dana Unger \\ Norwich Business School, University of East Anglia \\ Authors' Note \\ Ulrike Fasbender, Justus-Liebig-University Giessen, Work and Organizational \\ Psychology. Fabiola H. Gerpott, WHU - Otto Beisheim School of Management \& ARC \\ Centre of Excellence in Population Ageing Research (CEPAR). Dana Unger, Norwich \\ Business School, University of East Anglia. Correspondence concerning this manuscript \\ should be addressed to Ulrike Fasbender, Justus-Liebig-University Giessen, Work and \\ Organizational Psychology, Otto-Behaghel-Straße 10F, 35394 Giessen, Germany. Emails \\ should be sent to: Ulrike.Fasbender@psychol.uni-giessen.de.
}

Currently in press at Journal of Knowledge Management.

This paper is not the copy of record and may not exactly replicate the final, authoritative version of the article. Please do not copy or cite without authors' permission. The final article will be available, upon publication, via its DOI: 10.1108/JKM-11-2020-0856 


\begin{abstract}
Purpose: Knowledge exchange between older and younger employees enhances the collective memory of an organization and therefore contributes to its business success. In this study, we take a motivational perspective to better understand why older and younger employees share and receive knowledge with and from each other. Specifically, we focus on generativity striving-the motivation to teach, train, and guide others-as well as development striving-the motivation to grow, increase competence, and master something new-and argue that both motives need to be considered to fully understand intergenerational knowledge exchange.
\end{abstract}

Design/methodology/approach: We take a dyadic approach to disentangle how older employees' knowledge sharing is linked to their younger colleagues' knowledge receiving and vice versa. We applied an actor-partner interdependence model based on survey data from 145 age-diverse coworker dyads to test our hypotheses.

Findings: Results showed that older and younger employees' generativity striving affected their knowledge sharing, which in turn predicted their colleagues' knowledge receiving. Moreover, we found that younger employees were more likely to receive knowledge that their older colleagues shared with them when they scored higher (vs. lower) on development striving.

Originality: By studying the age-specific dyadic cross-over between knowledge sharing and knowledge receiving, this research adds to the knowledge exchange literature. We challenge the current age-blind view on knowledge exchange motivation and provide novel insights in the interplay of motivational forces involved in knowledge exchange between older and younger employees.

Keywords: knowledge sharing, knowledge receiving, older workers, younger workers, motivation at work, generativity and development striving 


\section{Give and Take? Knowledge Exchange between Older and Younger Employees as a Function of Generativity and Development Striving}

In the ever-evolving economy of the $21^{\text {st }}$ century, automation and technology changes rapidly transform work procedures and organizational processes, which makes knowledge exchange between employees more vital than ever (Balle et al., 2020; Bjorvatn \& Wald, 2020; Cascio \& Montealegre, 2016; Ng, 2020; Shujahat et al., 2020). A failure to ensure regular knowledge exchange can hinder organizations to adapt to the changing circumstances and requirements of the ever-evolving economy (Cheng et al., 2014; Sánchez-Polo et al., 2019). At the same time, the global workforce is getting older and more age-diverse, which requires employees of different ages to exchange knowledge with each other (Burmeister \& Deller, 2016; Ellwart et al., 2013; Schmidt \& Muehlfeld, 2017). In this regard, older and younger colleagues can benefit from each other's knowledge (i.e., ideas, information, and expertise relevant for one's task fulfillment; Bartol \& Srivastava, 2002) as they often possess distinct and nonredundant knowledge. For instance, older employees may share their expertise on organizational procedures or expert knowledge with their younger colleagues (Fasbender \& Gerpott, 2020; Wikström et al., 2018), while younger employees can demonstrate to older colleagues how to use new technologies (Gerpott et al., 2017). Knowledge exchange between older and younger employees is therefore highly relevant for the collective memory of an organization and contributes to its business success.

In focusing on the antecedents of knowledge exchange, research discovered different individual, interpersonal, organizational, and cultural characteristics that affect employees' knowledge sharing motivation, intention, and behavior (for a review see Nguyen et al., 2019; Wang \& Noe, 2010). A predominant notion in this literature is that employees who receive support from the organization or the interaction partner will be more likely to share their knowledge because they want to reciprocate (Cabrera et al., 2006; Gerpott, Fasbender, et al., 
2020; Hung et al., 2011; Kankanhalli et al., 2005; Lin, 2007; Schepers \& Van Den Berg, 2007). While such a social exchange perspective has provided important insights into external motivational forces of knowledge exchange, it neglects at least two important aspects. First, it cannot explain why some employees still share their knowledge, even though they may not receive any external rewards for doing so. Accordingly, what is currently missing is a finegrained and content-specific understanding of the intrinsic motivational forces that explain knowledge exchange between older and younger employees beyond the need to reciprocate. This is not only a theoretically relevant question but also practically important because the knowledge loss resulting from age-diverse employees being unmotivated to share knowledge is costly to organizations (e.g., capability gaps, higher learning, and training costs, slow task completion, and low productivity; Levallet \& Chan, 2019; Massingham, 2018).

Second, although knowledge sharing is a crucial part of the knowledge exchange process, it is nothing without knowledge receiving. Knowledge receiving entails that the interaction partner needs to encode and incorporate the shared information into their cognitive structures (Grand et al., 2016). While researchers and practitioners alike often take it for granted that shared knowledge is also received, we challenge this perspective and seek to shed light on the motivation of both interaction partners involved in the process - the knowledge sender (i.e., the person sharing knowledge) and the knowledge recipient (i.e., the person receiving knowledge) - to untangle the two underlying components of knowledge exchange.

Specifically, in this study, we take a dyadic approach to disentangle how older employees' knowledge sharing is linked to their younger colleagues' knowledge receiving and vice versa (i.e., dyadic cross-over). Integrating this dyadic approach with a motivational perspective that focuses on generativity and development striving as specific work motives, we develop and test a conceptual model of motivational forces that come into play in agediverse knowledge exchange. Generativity striving refers to the motivation to teach, train and guide other people, while development striving refers to the motivation to grow, increase 
one's competence, and master or understand something new at work (Kooij \& Van De Voorde, 2011). First, we explain that older and younger employees' generativity striving can enhance knowledge sharing, which in turn positively relates to younger and older colleagues' knowledge receiving. Building on theorizing in lifespan psychology (Carstensen, 1992; see also Kooij et al., 2011; Rudolph et al., 2018), we expect that the effect of generativity striving is more pronounced for older employees due to their limited future time at work that motivates them to live out their generativity striving rather quickly as compared to younger employees who have more time left at work. Second, we argue that the interaction partner's development striving moderates the indirect effects of one's generativity striving on the interaction partner's knowledge receiving via one's knowledge sharing. This is because employees with higher (vs. lower) development striving are more likely to pay attention to the knowledge that is shared by their interaction partner and actively invest resources to receive it. Based on two competing assumptions, we question whether there are age-group differences regarding the moderating role of development striving. As a result, we reveal that the joint effects of generativity striving (of the knowledge sender) and development striving (of the knowledge recipient) are crucial for the successful knowledge exchange between older and younger employees.

We aim to contribute to the literature in three ways. First, we extend the knowledge exchange literature by studying the age-group specific dyadic cross-over between knowledge sharing and knowledge receiving. Conceptually, this theorizing (a) takes the notion seriously that sharing knowledge does not automatically imply receiving knowledge and (b) goes beyond age-normative thinking of older employees as predominant knowledge senders (Burmeister, Fasbender, et al., 2018; Tempest, 2003). Empirically, we use an actor-partner interdependence model with a sample of 145 age-diverse coworker dyads (Cook \& Kenny, 2005 ) to test whether older and younger employees' knowledge sharing and receiving activities represent a bidirectional process (i.e., equally driven by the knowledge sharing and 
receiving of older and younger employees), which stands in contrast to the previously predominant and traditional unidirectional approach (i.e., equating older employees with knowledge senders). We thus contribute to the knowledge exchange literature by examining whether the same theoretical processes apply to both age-groups.

Second, we add to research on the individual antecedents of knowledge exchange, in particular employee motivation. While previous research has highlighted the importance of motivation (Gagné, 2009; Pee \& Lee, 2015; Siemsen et al., 2008), the majority of studies have investigated motivation from a social exchange perspective (Cabrera et al., 2006; Gerpott, Fasbender, et al., 2020; Hung et al., 2011; Kankanhalli et al., 2005; Lin, 2007; Schepers \& Van Den Berg, 2007), simplifying employee motivation as the wish to reciprocate received support from the management and organization. By pointing to generativity and development striving, we offer a more fine-grained and content-specific understanding of the intrinsic motivational forces that drive knowledge exchange between older and younger employees.

Third, we challenge the current age-blind view on knowledge exchange motivation, by probing age-group differences in the motivational forces that drive knowledge exchange between older and younger employees. While there is research on motivation in the general knowledge exchange literature (e.g., Gagné et al., 2019) as well as research on age-group differences in work motivation (e.g., Inceoglu et al., 2012; Kooij et al., 2011), it is relevant to understand these different streams in combination. By integrating these two literatures that can greatly benefit from each other's insights, we contribute to overcoming the age-blind view in the literature on knowledge exchange and offer a more nuanced perspective on the motivational forces involved in age-diverse knowledge exchange.

We will next describe the theoretical background and derive the hypotheses, beginning with the definition of our key construct, knowledge exchange (which consists of sharing and receiving knowledge), and an elaboration of the mutual exchange model (vs. the sourcerecipient model). We then introduce generativity and development striving as specific work 
motives, discuss age-group differences, and develop our hypotheses and research question accordingly. The next step is to specify our methodological approach taken (i.e., actor-partner interdependence model with a sample of 145 age-diverse coworker dyads), and to elaborate on the findings of our study. We then critically discuss the findings in light of our hypotheses and previous research. To conclude, we discuss the theoretical and practical implications of our study and provide directions for future research.

\section{Theoretical Background and Hypotheses Development}

Knowledge exchange means that knowledge is transferred from a source to a recipient (Shannon \& Weaver, 1949). Accordingly, knowledge exchange contains two elements: knowledge sharing and knowledge receiving (Reinholt et al., 2011; Wilkesmann et al., 2009). Knowledge sharing can be defined as the "act of making knowledge available to others within the organization" (Ipe, 2003, p. 341). In turn, knowledge receiving refers to the act of obtaining the shared knowledge from others within the organization. Knowledge receiving requires employees to decode and attach the new knowledge to their existing knowledge base (Burmeister et al., 2021; Grand et al., 2016). In this regard, employees must pay attention to the knowledge that is shared by their interaction partner and actively invest resources to receive it.

With regard to the knowledge exchange between older and younger employees, scholars have debated whether this communicative process is unidirectional (source-recipient model) or bidirectional (mutual exchange model). In the source-recipient model, older employees are seen as predominant knowledge senders due to their experience and expertise developed over the

years, while younger employees are understood as knowledge recipients as they tend to be seen as "half-baked" meaning that they may have acquired theoretical knowledge from school or university, but have less practical experience (Dunham \& Burt, 2011; Voelpel et al., 2012; Wikström et al., 2018). However, scholars have questioned this unidirectional view on knowledge exchange between younger and older employees (e.g., Burmeister et al., 2018; Gerpott et al., 2017; Harvey, 2012; Tempest, 2003). For instance, a case study by Harvey 
(2012) showed that mentoring sessions and group meetings generated mutual exchanges between the older and younger participants, pointing to a bidirectional process. We follow this bidirectional view and expect that successful knowledge exchange takes place when an older employee shares knowledge and their younger colleague receives (i.e., decodes and integrates) it as well as when a younger employee shares knowledge and the older colleague receives it. To better understand the knowledge sharing and receiving processes between older and younger employees, we next take a motivational perspective grounded in the lifespan literature.

\section{Wanting to Pass Something On: The Role of Generativity Striving in the Knowledge Exchange Process}

The term generativity striving was originally introduced by Erikson (1950), who defined generativity as the care and concern for future generations driven by both self-serving motives (i.e., wanting to feel competent and leave something behind by passing knowledge on) and other-serving motives (i.e., wanting something good for others). Organizational scholars position generativity striving as a relevant antecedent in the work context that can explain why people support others at work (e.g., Zacher et al., 2011, 2012). In the knowledge exchange context, scholars noted that generativity striving is a relevant motive for knowledge senders (Gerpott \& Fasbender, 2020). This is because the work environment provides an ideal opportunity to share experiences, skills, and knowledge with others (Fasbender et al., 2016; Mor-Barak, 1995). When a person provides knowledge or demonstrates skills, the interaction partner can potentially pick this up (i.e., receive the knowledge). Employees' generativity striving should positively relate to their knowledge sharing, which in turn prepares the ground for their colleagues' knowledge receiving. In other words, if employees do not provide any knowledge, there is no chance for their colleagues to decode new information and integrate it into existing knowledge structures. Accordingly, an employee's knowledge receiving is indirectly facilitated by their colleague's generativity striving. To summarize this line of reasoning, we hypothesize: 
Hypothesis 1a. Older colleague's generativity striving has a positive indirect effect on younger colleague's knowledge receiving via older colleague's knowledge sharing.

Hypothesis 1 b. Younger colleague's generativity striving has a positive indirect effect on older colleague's knowledge receiving via younger colleague's knowledge sharing. Although we expect that generativity striving results in more knowledge sharing for older and younger employees, our theorizing also considers that generativity striving constitutes a comparably more relevant driver of knowledge sharing for older employees than for their younger counterparts (Inceoglu et al., 2012; Kooij et al., 2011). Specifically, we argue that older employees are more likely to translate their generativity striving into action because they are more aware of their limited future time (Carstensen, 1992; Rudolph et al., 2018). In fact, empirical research has shown that with increasing age, employees' future time perspective at work (i.e., the perceived time and opportunities left until they retire) shrinks, which entails that older employees are more aware that they have less time left to pass on their knowledge to colleagues (Rudolph et al., 2018). Accordingly, older employees should feel a higher sense of urgency to act on their generativity striving (e.g., by sharing their knowledge) as compared to their younger counterparts for whom the future is comparatively still open (cf. Fasbender et al., 2019). To summarize, we expect that the effect of generativity striving is more pronounced for older employees due to their limited future time perspective that demands them to act rather quickly as compared to younger employees who have more time left at work. Stated formally, we hypothesize:

Hypothesis 2. Older colleague's generativity striving has a stronger effect on older colleague's knowledge sharing than younger colleague's generativity striving has on younger colleague's knowledge sharing.

\section{Wanting to Grow: The Moderating Role of Development Striving}

It is often taken for granted that knowledge sharing leads to knowledge receiving. Yet, the motivational orientation of the knowledge recipient greatly matters such that the provided 
knowledge must hit "a prepared ground" in the sense that the interaction partner has to be motivated to receive the knowledge. Knowledge receiving requires mental effort because the new information shared by the colleague is often ambiguous and it requires additional processing to interpret and integrate the new with existing knowledge (Burmeister et al., 2021; Grand et al., 2016). That is, employees need to translate the information they perceive from the knowledge sender into knowledge they understand and can remember. Following through with our motivational perspective on knowledge exchange, we argue that the link between sharing and receiving knowledge can be supported by development striving of the knowledge recipient. Specifically, we argue that employees with higher development striving are more likely to invest mental effort to engage in deep processing of information that is shared by a colleague, thereby transforming it into knowledge that is remembered. In contrast, employees with lower development striving may pick up easily accessible information but are unlikely to invest attentional resources to decode and integrate more complex or large amounts of shared expertise. In other words, we argue that development striving is a necessary condition for receiving knowledge that has been shared by another person. Supporting this argument, scholars have emphasized that the general interest in and perceived relevance of learning new information facilitates whether an employee will retrieve information that is shared in a training program (Bell et al., 2017; Blume et al., 2010). The motivational component is particularly important when it comes to acquiring and interpreting information shared by a colleague as compared to learning about facts from other sources (e.g., books) because social interactions carry a higher degree of information ambiguity that makes the reception of knowledge more challenging (Grand et al., 2016). Development striving should therefore strengthen the positive relation between knowledge sharing and knowledge receiving. In sum, we propose:

Hypothesis 3a. Younger colleague's development striving moderates the effect of older colleague's knowledge sharing on younger colleague's knowledge receiving in a 
way that the positive effect is stronger when younger colleague's development striving is higher (vs. lower).

Hypothesis 3b. Older colleague's development striving moderates the effect of younger colleague's knowledge sharing on older colleague's knowledge receiving in a way that the positive effect is stronger when older colleague's development striving is higher (vs. lower).

Bringing together our arguments on (1) the indirect cross-over effect of a focal person's generativity striving on the interaction partner's knowledge receiving via the focal person's knowledge sharing, and (2) the moderating role of the interaction partner's development striving, we argue for an integrated model that considers generativity striving as a motivational driver of knowledge sharing, which sets the ground for a dyadic cross-over effect on knowledge receiving that is moderated by development striving.

Hypothesis 4a. Younger colleague's development striving moderates the indirect effect of older colleague's generativity striving on younger colleague's knowledge receiving (via older colleague's knowledge sharing) in a way that the positive indirect effect is stronger when younger colleague's development striving is higher (vs. lower).

Hypothesis $4 \boldsymbol{b}$. Older colleague's development striving moderates the indirect effect of younger colleague's generativity striving on older colleague's knowledge receiving (via younger colleague's knowledge sharing) in a way that the positive indirect effect is stronger when older colleague's development striving is higher (vs. lower).

\section{Age-Group Differences in the Moderating Role of Development Striving}

An interesting question arises when consulting the literature on development striving and age because one may derive two competing assumptions about whether development striving is more important for older or younger employees when it comes to receiving knowledge that is shared by one's colleague. On the one side, age-group differences in existing knowledge structures could affect how employees receive knowledge that has been 
shared by their colleagues. In this regard, development striving may be more relevant for younger employees to compensate for the comparatively lower existing knowledge structures that are necessary to effectively integrate new knowledge (Grand et al., 2016). Older employees have accumulated more knowledge over the years (Salthouse, 2012), which should make it easier for them to decode the knowledge that their younger colleagues share with them and attach the new knowledge to the existing one. Older employees' knowledge receiving should therefore depend comparatively less on their development striving as they do not need to invest much additional energy into the knowledge integration process. In contrast, younger employees have accumulated less knowledge than their older counterparts (Salthouse, 2012), which makes it harder for them to decode and connect the new knowledge with the existing one. Younger employees may compensate for this disadvantage in existing knowledge structures with development striving that motivates them to actively invest attentional resources to recognize and process the knowledge that their older colleagues shared with them. As a result, development striving should be at least as (if not more) relevant for younger than older employees' knowledge receiving.

On the other side, age norms and related role expectations could affect how employees receive knowledge that has been shared by their colleagues. Age norms are "widely shared judgments of the standard or typical age of individuals holding a role" in an organization (Lawrence, 1988, p. 310). Due to these age norms, older employees tend to be associated with the role as knowledge sender (Dunham \& Burt, 2011; Voelpel et al., 2012; Wikström et al., 2018), while younger employees tend to be associated with the role as knowledge recipient (Burmeister, Fasbender, et al., 2018). These normative expectations make the reverse knowledge exchange in which knowledge is exchanged from younger to older employees more challenging. While younger employees' knowledge receiving from their older colleagues is in line with organizational age norms, older employees who receive knowledge from their younger colleagues deviate from organizational age norms (Tempest, 2003). 
Hence, being open to the reception of knowledge from younger colleagues may require a strong motivational engagement from older employees. As a result, development striving should be at least as (if not more) relevant for older than younger employees' knowledge receiving. Given that both competing assumptions are conceivable, we pose the following research question:

Research Question 1. Does the moderating role of development striving on the relation between knowledge sharing and knowledge receiving differ for younger and older employees?

\section{Method}

\section{Procedure and Sample}

From January 2019 to March 2020, we collected data from age-diverse coworker dyads in Germany. We selected participants based on four criteria specified in the literature on age, dyadic relationships, and knowledge transfer. First, participants must be working, because we are interested in understanding knowledge exchange at work rather than in nonwork contexts (Lee, 2019). Relatedly, we chose 20 hours as a cut-off to ensure that participants have sufficient opportunity to engage in knowledge exchange at work (Burmeister et al., 2019; Gerpott, Fasbender, et al., 2020). Second, being peers of similar status is relevant, because a hierarchical status difference (i.e., a disciplinary responsibility between employees) may limit the direction of the knowledge exchange from the statushigher to the status-lower employee (Fasbender \& Gerpott, 2020; Liden et al., 2016). Third, having regular work contact matters because by having contact, coworkers have the opportunity to exchange knowledge and support each other at work (Fasbender et al., 2020). Fourth, we chose an age difference of ten years to test our research model in age-diverse dyads in accordance with our theorizing (cf. Burmeister, van der Heijden, et al., 2018; Burmeister, Wang, et al., 2020). 
Collecting dyadic data is challenging. Using personal networks can be an effective way to deal with these challenges because they help to establish contact and maintain highquality communication with the participants. One way to utilize and increase the size of personal networks is student-recruited sampling. Student-recruited sampling is known to large sample sizes and ensure statistical power (Wheeler et al., 2014). When compared with samples not recruited by students, student-recruited samples tend to have similar demographic characteristics and yield similar relationship between variables (Wheeler et al., 2014).

Furthermore, this sampling technique yields heterogeneous samples (Demerouti \& Rispens, 2014). We therefore instructed students to recruit participants within their networks, allowing for generalization across different jobs and industries (for a similar procedure, see Burmeister, Fasbender, et al., 2018; Burmeister, Wang, et al., 2020). Specifically, we asked students to contact employees with a short advertisement text for the study. Interested employees and their colleagues received a personalized link to the online survey via email. Participants were asked to individually complete the survey. We used participant codes to match the data from older and younger colleagues. The code was allocated to the participants beforehand and sent with the personalized link to the online survey. As an incentive, participants were offered to take part in a draw for receiving a voucher worth $€ 10$.

We received complete data from 165 dyads. Of these, 20 dyads were removed because they had an age difference of less than ten years, consequently yielding a final sample of 145 age-diverse coworker dyads ( $N=290$ employees). The average age of younger colleagues was 29.70 years $(S D=5.38)$, while older colleagues were, on average, 51.81 years $(S D=$ 6.71). In total, 127 dyads (87.6\%) worked at least one year together, 74 dyads (51.0\%) worked at least three years together, and four dyads (2.8\%) worked for more than ten years together. The majority of the sample was female (182 participants; $62.8 \%$ ) and worked in white-collar jobs (208 participants; 71.7\%). We sampled participants from various industries, 
that is, for instance, health care (19.7\%), civil service (19.3\%), manufacturing (14.5\%), technology, media, and communication $(7.2 \%)$, as well as finance and insurance $(6.2 \%)$.

\section{Measures}

All measures were pre-tested within the research team to ensure that items were coherent and face-valid.

Generativity striving. We used the three-item scale developed by Kooij and Van De Voorde (2011) to assess older and younger colleague's generativity striving. A sample item was "How important is the chance to teach and train others for you?". The items are based on a fivepoint rating scale $(1=$ not important at all, $5=$ very important $)$. Cronbach's alpha was .83 .

Knowledge sharing. In self-ratings, we measured older and younger colleagues' knowledge sharing with the three-item scale by Wilkesmann et al. (2009) on a five-point rating scale ( 1 = strongly disagree, $5=$ strongly agree $)$. A sample item was "I show my colleague special procedures so that they can learn them." We adapted the scale so that older and younger colleagues assessed knowledge sharing with their peer (as opposed to general knowledge sharing). Cronbach's alpha was .76.

Knowledge receiving. Older and younger colleagues rated their knowledge receiving by means of the corresponding four-item scale by Wilkesmann et al. (2009) on a five-point rating scale $(1=$ strongly disagree, $5=$ strongly agree $)$. A sample item was "I make an effort to receive knowledge from my colleague." We modified the scale to capture the specific interaction with the participating colleague. Cronbach's alpha was .84.

Development striving. We measured older and younger colleagues' development striving with three items developed by Kooij and Van De Voorde (2011). A sample item was "How important is the opportunity to learn something new for you?". The items are based on a five-point rating scale $(1=$ not important at all, $5=$ very important $)$. Cronbach's alpha was .83. 
Control variables. We controlled for participants education (binary coded with $0=n o$ university degree and 1 = university degree) and workload. Holding a university degree should go along with greater resources to share knowledge as well as more credibility on the side of the recipient (Kuyken et al., 2009). Furthermore, workload might decrease the opportunities for both knowledge sharing and receiving (see Gerpott, et al., 2020). We measured workload by means of Wu and colleague's (2014) three-item scale (e.g., "To what extent do you feel there is not enough time for you to finish your work?"; with responses ranging from $1=$ strongly disagree, 5 = strongly agree). Cronbach's alpha was .78.

\section{Analytic Strategy}

We applied the actor-partner interdependence model (APIM; Kenny et al., 2006; Ledermann et al., 2011) to account for the nestedness of older and younger colleague's dyadic data and to examine whether the same theoretical process applies to both dyad members (Fitzpatrick et al., 2016). The APIM distinguishes between intra- and interpersonal relationships as so-called actor and partner effects. Our research model comprises both effects. The effects of older and younger colleagues' generativity striving on their own knowledge sharing constitute an actor effect. The relationship between one (e.g., the older) colleague's knowledge sharing and the other (e.g., the younger) colleague's knowledge receiving is a partner effect. We always tested two actor and two partner effects per dyads. We used Mplus 8.3 to analyze our data (Muthén \& Muthén, 2019).

We tested all hypotheses simultaneously in one path model which was modeled as follows: First, we modeled actor and partner effects of generativity striving on knowledge sharing and included actor and partner effects of knowledge sharing on knowledge receiving. Second, actor and partner effects of development striving were modeled onto both colleagues' knowledge receiving (see also Cohen et al., 2003). Furthermore, the interaction terms older (younger) colleague's knowledge sharing $\times$ younger (older) colleague's development striving were inserted as predictors of younger (older) colleague's knowledge receiving. We centered 
the predictors around the sample mean before computing the interaction terms (Aiken \& West, 1991). Third, we included the control variables (i.e., education and workload) as predictors of knowledge sharing and knowledge receiving. Conducting the path analysis with and without control variables yielded the same results for our hypothesized effects. In line with Spector and Brannick (2011), we therefore present the results without control variables.

To examine the indirect effects of generativity striving on knowledge receiving via knowledge sharing in both dyad members, we computed bootstrapped 95\%-confidence intervals (CI) with 10,000 resamples making use of a Maximum Likelihood (ML) estimation (Preacher \& Hayes, 2008). Finally, we calculated conditional indirect effects at different levels of older and younger colleagues' development striving (i.e., above and below $1 S D$ of the mean) to shed light on development striving's moderating role in both processes.

\section{Results}

\section{Preliminary Analyses}

Table 1 shows the means, standard deviations, and inter-correlations of all variables. Table 2 shows the results of our multi-level confirmatory factor analyses, providing evidence for the study variables' distinctness. Factor loadings varied from .62 to .98 and were all significant $(p<.001)$.

\section{Hypothesis Testing}

The fit of our hypothesized model was good: $\chi^{2}(15)=18.139$, root-mean-square error of approximation $(\mathrm{RMSEA})=.038$; comparative fit index $(\mathrm{CFI})=.964$; Tucker-Lewis index $(\mathrm{TLI})=.927 ;$ standardized root-mean residual $(\mathrm{SRMR})=.048$. Figure 1 and Table 3 depict the results of the actor-partner-interdependence model.

Hypotheses 1a and $1 \mathrm{~b}$ addressed the indirect effects of older (younger) colleague's generativity striving on younger (older) colleague's knowledge receiving via older (younger) colleague's knowledge sharing. We found preliminary evidence when inspecting the coefficients of the relevant a- and b-paths. The positive actor effects of generativity striving 
on knowledge sharing were significant (older colleague: $b=.51, p<.001$; younger colleagues: $b=.38, p<.001)$. Furthermore, we found that older colleague's knowledge sharing predicted younger colleague's knowledge receiving $(b=.23, p=.002)$. There was also a significant and positive effect of younger colleague's knowledge sharing on older colleague's knowledge receiving $(b=.17, p=.038)$. The positive indirect effect of older colleague's generativity striving on younger colleague's knowledge receiving via older colleague's knowledge sharing was significant as the CI did not include zero (estimate $=.117$, $95 \%$ CI $[.036 ; .217])$. Similarly, the positive indirect effect of younger colleague's generativity on older colleague's knowledge receiving via younger colleague's colleague knowledge sharing was significant (estimate $=.063,95 \%$ CI $[.004 ; .144])$. In sum, these findings support Hypotheses $1 \mathrm{a}$ and $1 \mathrm{~b}$.

In Hypothesis 2, we argued that the effect of older colleague's generativity striving on older colleague's knowledge sharing is stronger than the effect of younger colleague's generativity striving on younger colleague's knowledge sharing. To test this hypothesis, we inspected the $95 \%$ CI of the difference between both indirect effects. As the $95 \%$ CI included zero (estimate $=.127 ; 95 \%$ CI [-.128; 398.]), we rejected Hypothesis 2 .

Hypotheses $3 \mathrm{a}$ and $3 \mathrm{~b}$ addressed the moderating role of younger (older) colleague's development striving on the effect of older (younger) colleague's knowledge sharing on younger (older) colleague's knowledge receiving. On the one hand, we found that the interaction term older colleague's knowledge sharing $\times$ younger colleague's development striving predicted younger colleague's knowledge receiving $(b=.31, p=.023)$. We further inspected the simple slopes at one $S D$ above and below the mean of the moderator younger colleague's development striving. The results showed that the relationship between older colleague's knowledge sharing and younger colleague's knowledge was stronger at higher levels of younger colleague's development striving ( simple slope $=.39, p<.001$ ), whereas it was not significant at lower levels of the moderator (simple slope $=.07, p=.496$ ). Figure 2 
depicts the interaction effect. Taken together, these findings support Hypothesis 3a. On the other hand, the interaction between younger colleague's knowledge sharing and older colleague's development striving did not explain variance in older colleague's knowledge receiving $(b=.11, p=.337)$. Thus, we found no support for Hypothesis $3 \mathrm{~b}$.

Hypotheses $4 \mathrm{a}$ and $4 \mathrm{~b}$ addressed the moderating role of younger (older) colleague's development striving on the indirect effect of older (younger) colleague's generativity striving on younger (older) colleague's knowledge receiving via older (younger) colleague's knowledge sharing. First, we found that the indirect effect of older colleague's generativity striving on younger colleague's knowledge receiving via older colleague's knowledge sharing was stronger at higher levels of younger colleague's development striving (estimate $=.198$, $95 \%$ CI $[.083 ; .351])$, whereas it was not significant at lower levels of younger colleague's development striving $($ estimate $=.035,95 \%$ CI $[-.067 ; .128]$; difference $=.163,95 \%$ CI $[.047$; .359]). Moreover, the index of the moderated mediation was significant (estimate $=.157 ; 95 \%$ CI $[.045 ; .346])$. These results are in line with Hypothesis 4a. Second, we found that the indirect effect of younger colleague's generativity striving on older colleague's knowledge receiving via younger colleague's knowledge sharing was significant at higher levels of older colleague's development striving (estimate $=.091,95 \%$ CI $[.019 ; .217])$, but not at lower levels of the moderator (estimate $=.034,95 \%$ CI $[-.066 ; .128]$ ). However, the difference between the two conditional indirect effects (difference $=.058,95 \%$ CI $[-.053 ; .218]$ ) and the index of the moderated mediation (estimate $=.040 ; 95 \% \mathrm{CI}[-.037 ; .153]$ ) were not significant. Therefore, Hypothesis $4 \mathrm{~b}$ was not supported.

\section{Exploratory Analysis}

Research Question 1 asked whether the role of development striving in strengthening the relationship between one colleague's knowledge sharing and the other colleague's knowledge receiving differs for older and younger colleagues. To answer this question, we inspected the interaction terms of older (younger) colleague's knowledge sharing $\times$ younger 
(older) colleague's development striving as predictors of knowledge receiving. We found that the interaction effect of older colleague's knowledge sharing $\times$ younger colleague's development striving was significant $(b=.31, p=.023)$, whereas the interaction term younger colleague's knowledge sharing $\times$ older colleague's development striving was not $(b=.11, p=$ .337). Hence, we found evidence supporting the idea that development striving plays a different role for older and younger employees in the association between one colleague's knowledge sharing and the other colleague's knowledge receiving.

\section{Discussion}

Considering the demographic and technological trends that shape the economy of the $21^{\text {st }}$ century, our research aimed to gain a better understanding of the motivational forces that drive knowledge exchange between older and younger employees. Results of an actor-partner interdependence model based on a sample of 145 age-diverse coworker dyads revealed that older and younger employees' generativity striving affected their knowledge sharing, which in turn predicted their counterparts' knowledge receiving. These findings demonstrate that older employees' knowledge sharing facilitates their younger colleagues' knowledge receiving and vice versa, that younger employees' knowledge sharing facilitates their older colleagues' knowledge receiving. These results add to previous research that has investigated knowledge exchange between older and younger employees from a unidirectional (e.g., Fasbender \& Gerpott, 2020; Wikström et al., 2018) and a bidirectional view (e.g., Gerpott et al., 2017; Harvey, 2012; Tempest, 2003). Furthermore, our findings are in line with previous research which has pointed to the relevance of generativity striving in knowledge exchange (e.g., Burmeister, Fasbender, et al., 2018; Burmeister, Wang, et al., 2020). Different than expected, generativity striving was, however, equally important for older and younger employees. Whereas previous research suggested that generativity striving constitutes a more relevant motive for older than for younger employees (e.g., Inceoglu et al., 2012; Kooij et al., 2011), we found no differences with regard to the level of generativity striving of older vs. 
younger employees, nor its motivating effect on employees' knowledge sharing. Our findings therefore shed a different light on the role of generativity striving at work.

Moreover, we found that the knowledge recipient's development striving moderated the indirect effect of the interaction partner's generativity striving on their knowledge receiving via the interaction partner's knowledge sharing behavior. This entails that employees with higher (vs. lower) development striving benefit more from a colleague with higher (vs. lower) generativity striving because the respective colleague would share more knowledge with them, which employees with higher (vs. lower) development striving are more likely to receive. The reinforcing role of development striving in linking the other person's knowledge sharing with one's own knowledge receiving was, however, only relevant for younger employees who received knowledge from their older counterparts. With regard to our research question, these findings add to previous research showing that younger employees have accumulated less knowledge than their older counterparts (Salthouse, 2012), which explains why it is harder for them to decode and connect the new knowledge with the existing one (Grand et al., 2016). That is, our findings implicate that younger employees compensate the lower accumulated knowledge with development striving that motivates them to receive the knowledge that their older colleagues shared with them. On the contrary, our findings do not support the notion that normative expectations, which see younger rather than older employees as knowledge recipients (Dunham \& Burt, 2011; Voelpel et al., 2012; Wikström et al., 2018), would make the reverse knowledge exchange from younger to older employees more challenging and would therefore require a strong motivational engagement from older employees (as indicated by their development striving). Rather, our findings demonstrate that development striving helps specifically younger employees to better receive the knowledge shared by their older colleagues. 


\section{Theoretical Implications}

Our findings contribute to the literature in different ways. First, we add to the knowledge exchange literature by studying the age-group specific dyadic cross-over between sharing and receiving knowledge. In line with previous research (e.g., Gerpott et al., 2017; Harvey, 2012; Tempest, 2003), we found that knowledge exchange between older and younger employees is a bidirectional process, where older and younger employees learn from each other. We therewith challenge the age-normative thinking (Dunham \& Burt, 2011; Voelpel et al., 2012; Wikström et al., 2018), where older employees are seen as knowledge senders, whereas younger employees are seen as knowledge receivers. Instead, we highlight the mutual exchange of knowledge between age-diverse employees.

Second, our findings contribute to the research on the individual antecedents of knowledge exchange, in particular employee motivation (Gagné, 2009; Pee \& Lee, 2015; Siemsen et al., 2008). In line with previous research (Gagné et al., 2019; Nguyen et al., 2019), we found that intrinsic motivational forces can support knowledge exchange. A fine-grained and content-specific understanding of the intrinsic motivational forces, namely our focus on generativity striving and development striving, was helpful because it allowed us to assess which motivational force is useful to whom (knowledge sender or knowledge recipient). Specifically, we showed that generativity striving is useful to the knowledge sender, while development striving is useful to the knowledge recipient and that their combination helps to maximize the success of the collective knowledge exchange process.

Third, our research adds to a better understanding of age-group similarity and difference with regard to the interplay of motivational forces involved in knowledge exchange. On the one hand, we found age-group similarity because generativity striving was equally important to both age-groups, older and younger employees. These findings contradict lifespan research that suggests that generativity should become more important with increasing age (e.g., Inceoglu et al., 2012; Kooij et al., 2011). Instead, our results highlight 
that generativity striving is also relevant to younger people (Ackerman et al., 2000; Pratt \& Lawford, 2014). As such, our findings indicate that generativity striving is a universal human motive. On the other hand, we found age-group difference because development striving was only relevant for younger knowledge recipients. One plausible explanation for our findings is that younger knowledge recipients compensate for lower existing knowledge structures with development striving that motivates them to effectively integrate new knowledge (Grand et al., 2016). Overall, by uncovering age-group similarity and difference in motivational forces, our research contributes to a more profound understanding of the role of age diversity in knowledge exchange processes.

\section{Practical Implications}

This study also has several practical implications that could help organizations in general and managers in particular to enhance knowledge exchange between age-diverse employees. First, the findings emphasize the importance of the bidirectional nature of knowledge exchange in which older and younger employees equally act as knowledge senders and recipients. Accordingly, organizations should emphasize in their communication that all employees - irrespective of their age - are capable of, expected to, and appreciated for sharing their knowledge. Second, considering that generativity striving constitutes a driver of knowledge sharing, managers are well advised to design work in a way that enhances generativity striving (Henry et al., 2015). For example, they could introduce mentoring programs that include traditional tandems (i.e., older mentor, younger mentee) as well as reverse mentoring tandems (i.e., younger mentor, older mentee; Chaudhuri \& Ghosh, 2012), foster peer-to-peer learning initiatives, or establish institutionalized feedback systems (a concept similar to providing opportunities for generativity, Truxillo et al., 2012). Third, managers should communicate on a day-to-day basis that passing on knowledge is appreciated in the organization, thereby taking particular care of using an inclusive language of knowledge exchange that describes learning as an age-independent activity at work 
(Tempest, 2003). For example, managers may be particularly sensitized that they equally encourage older and younger employees to take part in skills training programs and receive regular development opportunities. Such measures avoid that age norms keep older employees from seeing themselves only as knowledge senders and instead also clearly address them as knowledge receivers (Burmeister, Fasbender, et al., 2018). Lastly, our research can also be interesting for employees themselves who may not have been thinking of knowledge exchange as an active process that involves deliberate engagement. That is, when an employee is aware that sharing knowledge does not automatically mean that others will pick it up, they may put more effort into following up for example with clarification questions to see whether what they shared was also received. Similarly, making employees aware that knowledge receiving is a purposeful act involving activities such as observing colleagues, asking for advice, and understanding which knowledge one can possibly obtain from others at work may be an important step for broadening employees' understanding of workplace learning.

\section{Limitations and Future Research Directions}

Our dyadic design allowed us to capture the unique perspectives of older and younger employees as knowledge senders and knowledge receivers. However, there are relevant limitations to be addressed. First, the survey design entails a risk of commonmethod bias and a possibility that participants may have over-reported their knowledge sharing as it constitutes a socially desirable behavior. Yet, although these concerns are possible when testing main effects, they do not explain the complexity of the observed interaction effects (Gerpott et al., 2019; Siemsen et al., 2009), nor can they explain the observed cross-over effects between employees (Podsakoff et al., 2012). Nevertheless, future research may want to test the hypothesized relationships using objective measures of knowledge sharing and/or receiving. For example, scholars could record meetings between age-diverse employees to objectively code verbal expressions of knowledge sharing 
(Gerpott, Lehmann-Willenbrock, et al., 2020), and subsequently ask employees to visualize the received knowledge to grasp which types of information they obtained from their colleague in the respective meeting (Burmeister, Gerpott, et al., 2020).

Second, the cross-sectional design of our study does not allow for causal inferences. One possibility to address this concern is the implementation of a longitudinal design in which employees' motives, their knowledge sharing and knowledge receiving responses are measured at different time points. Such a design may help to derive causal priorities between the investigated relationships (M. Wang et al., 2017). Furthermore, scholars may implement an experimental design by manipulating the salience of generativity and development striving to test their (interactive) effects on knowledge sharing and knowledge receiving, respectively. Although motives constitute dispositional and rather stable attributes, they can be addressed and changed in the short-term by using a priming procedure (i.e., providing cues in form of text or picture material that activate certain motives in a person's memory). Specifically, scholars may use priming cues to increase people's awareness of their generativity or development motives, respectively, which should then influence their subsequent behavior (Hagood \& Gruenewald, 2018). Alternatively, scholars could also think about a field intervention in which they target job design, such that they create more opportunities for generativity (e.g., mentoring programs, institutionalized peer-to-peer learning initiatives) and opportunities for development (e.g., brownbag lunches, challenging work tasks) in employees' daily job (Henry et al., 2015).

Third, we did not differentiate between different types of knowledge the interaction partners exchanged. However, it is conceivable that generativity and development striving matter differently for the exchange of different knowledge types. For example, we would expect development striving to be particularly important for receiving complex expert knowledge that cannot yet be connected to existing cognitive knowledge structures and to be less relevant for receiving simple factual knowledge (Grand et al., 2016). Several taxonomies 
of knowledge types that represent varying degrees of knowledge complexity (e.g., knowwhat, know-how, know-when, and know-why; Alavi \& Leidner, 2001; Jiang et al., 2020) exist that could be used to further understand the motivational forces involved in sharing and receiving different types of knowledge.

Fourth, we did not account for the role of personality in our study. Specifically, proactive personality (e.g., expressed in taking charge and showing personal initiative) could be relevant because proactive employees are more committed at work, perform better, and tend to show more prosocial and other-oriented behavior (Klehe et al., 2021; Spitzmuller et al., 2015; Tornau \& Frese, 2013). It is likely that proactive employees also engage in more knowledge sharing and receiving at work. Moreover, it conceivable that employees' motives are determined by their personality. For example, research in training and development found that proactive individuals show higher transfer intentions through higher levels of motivation to learn (Roberts et al., 2018). Scholars may use valid personality assessment measures (e.g., Bateman \& Crant, 1993; Claes et al., 2005) to investigate the role of personality (e.g., proactive personality) in knowledge exchange between younger and older employees.

\section{Conclusion}

Many organizations have realized that knowledge exchange is crucial for their success, particularly against the backdrop of an aging workforce that makes it necessary to put more effort into maintaining the unique knowledge of older employees who will retire in the next years. However, although managers often put external reward and/or knowledge management systems in place, they tend to oversee that age-diverse employees may possess specific intrinsic motives that encourage them to spend time and energy on sharing and receiving knowledge. We hope that our research contributes to putting these intrinsic motives into the spotlight, and sensitizes researchers and practitioners alike to consider that successful knowledge exchange requires both sides of the coin: Employees who are willing to share knowledge, and employees who are willing to take it. 


\section{References}

Ackerman, S., Zuroff, D. C., \& Moskowitz, D. S. (2000). Generativity in midlife and young adults: Links to agency, communion, and subjective well-being. The International Journal of Aging and Human Development, 50(1), 17-41. https://doi.org/10.2190/9F51LR6T-JHRJ-2QW6

Aiken, L. S., \& West, S. G. (1991). Multiple regression: Testing and interpreting interactions. Sage Publications.

Alavi, M., \& Leidner, D. E. (2001). Knowledge management and knowledge management systems: Conceptual foundations and research issues. MIS Quarterly, 25, 107-136. https://doi.org/10.2307/3250961

Balle, A. R., Oliveira, M., \& Curado, C. M. M. (2020). Knowledge sharing and absorptive capacity: interdependency and complementarity. Journal of Knowledge Management, 24(8), 1943-1964. https://doi.org/10.1108/JKM-12-2019-0686

Bartol, K. M., \& Srivastava, A. (2002). Encouraging knowledge sharing: The role of organizational reward systems. Journal of Leadership \& Organizational Studies, 9, 6476. https://doi.org/10.1177/107179190200900105

Bateman, T. S., \& Crant, J. M. (1993). The proactive component of organizational behavior: A measure and correlates. Journal of Organizational Behavior, 14, 103-118. https://doi.org/10.1002/job.4030140202

Bell, B. S., Tannenbaum, S. I., Kevin Ford, J., Noe, R. A., \& Kraiger, K. (2017). 100 years of training and development research: What we know and where we should go. Journal of Applied Psychology, 102(3), 305-323. https://doi.org/10.1037/ap10000142

Bjorvatn, T., \& Wald, A. (2020). The impact of time pressure on knowledge transfer effectiveness in teams: trust as a critical but fragile mediator. Journal of Knowledge Management, 24(10), 2357-2372. https://doi.org/10.1108/JKM-05-2020-0379

Blume, B. D., Ford, J. K., Baldwin, T. T., \& Huang, J. L. (2010). Transfer of training: A meta-analytic review. Journal of Management, 36(4), 1065-1105. https://doi.org/10.1177/0149206309352880

Burmeister, A., Alterman, V., Fasbender, U., \& Wang, M. (2021). Too much to know? The cognitive demands of daily knowledge seeking and the buffering role of contact quality. Journal of Applied Psychology.

Burmeister, A., \& Deller, J. (2016). Knowledge retention from older and retiring workers: What do we know, and where do we go from here? Work, Aging and Retirement, 2, 87104. https://doi.org/10.1093/workar/waw002

Burmeister, A., Fasbender, U., \& Deller, J. (2018). Being perceived as a knowledge sender or knowledge receiver: A multistudy investigation of the effect of age on knowledge transfer. Journal of Occupational and Organizational Psychology, 91, 518-545. https://doi.org/10.1111/joop.12208

Burmeister, A., Fasbender, U., \& Gerpott, F. H. (2019). Consequences of knowledge hiding: The differential compensatory effects of guilt and shame. Journal of Occupational and Organizational Psychology, 92, 281-304. https://doi.org/10.1111/joop.12249

Burmeister, A., Gerpott, F. H., Hirschi, A., Scheibe, S., Pak, K., \& Kooij, D. (2020). Reaching the Heart or the Mind? Test of two Theory-Based Training Programs to Improve Interactions Between Age-Diverse Coworkers. Academy of Management Learning \& Education, July. https://doi.org/10.5465/amle.2019.0348

Burmeister, A., van der Heijden, B., Yang, J., \& Deller, J. (2018). Knowledge transfer in agediverse coworker dyads in China and Germany: How and when do age-inclusive human resource practices have an effect? Human Resource Management Journal, 28, 605-620. https://doi.org/10.1111/1748-8583.12207

Burmeister, A., Wang, M., \& Hirschi, A. (2020). Understanding the motivational benefits of knowledge transfer for older and younger workers in age-diverse coworker dyads: An actor-partner interdependence model. Journal of Applied Psychology, 105(7), 748-759. https://doi.org/10.1037/ap10000466

Cabrera, A., Collins, W. C., \& Salgado, J. F. (2006). Determinants of individual engagement in knowledge sharing. International Journal of Human Resource Management, 17(2), 245-264. https://doi.org/10.1080/09585190500404614

Carstensen, L. L. (1992). Social and emotional patterns in adulthood: Support for 
socioemotional selectivity theory. Psychology and Aging, 7, 331-338.

Cascio, W. F., \& Montealegre, R. (2016). How technology is changing work and organizations. Annual Review of Organizational Psychology and Organizational Behavior, 3, 349-375. https://doi.org/10.1146/annurev-orgpsych-041015-062352

Chaudhuri, S., \& Ghosh, R. (2012). Reverse mentoring: A social exchange tool for keeping the boomers engaged and millennials committed. Human Resource Development Review, 11(1), 55-76. https://doi.org/10.1177/1534484311417562

Cheng, H., Niu, M. S., \& Niu, K. H. (2014). Industrial cluster involvement, organizational learning, and organizational adaptation: An exploratory study in high technology industrial districts. Journal of Knowledge Management, 18(5), 971-990. https://doi.org/10.1108/JKM-06-2014-0244

Claes, R., Beheydt, C., \& Lemmens, B. (2005). Unidimensionality of abbreviated proactive personality scales across cultures. Applied Psychology, 54(4), 476-489. https://doi.org/10.1111/j.1464-0597.2005.00221.x

Cohen, J., Cohen, P., West, S. G., \& Aiken, L. S. (2003). Applied multiple regression/correlation analysis for the behavioral sciences. Erlbaum.

Cook, W. L., \& Kenny, D. A. (2005). The actor-partner interdependence model: A model of bidirectional effects in developmental studies. International Journal of Behavioral Development, 29(2), 101-109. https://doi.org/10.1080/01650250444000405

Demerouti, E., \& Rispens, S. (2014). Improving the image of student-recruited samples: A commentary. Journal of Occupational and Organizational Psychology, 87(1), 34-41. https://doi.org/10.1111/joop.12048

Dunham, A. H., \& Burt, C. D. B. (2011). Organizational memory and empowerment. Journal of Knowledge Management, 15, 851-868. https://doi.org/10.1108/13673271111174366

Ellwart, T., Bündgens, S., \& Rack, O. (2013). Managing knowledge exchange and identification in age diverse teams. Journal of Managerial Psychology, 28, 950-972. https://doi.org/10.1108/JMP-06-2013-0181

Erikson, E. H. (1950). Childhood and Society. W. W. Norton.

Fasbender, U., Burmeister, A., \& Wang, M. (2020). Motivated to be socially mindful: Explaining age differences in the effect of employees' contact quality with coworkers on their coworker support. Personnel Psychology, 73(3), 407-430. https://doi.org/10.1111/peps.12359

Fasbender, U., \& Gerpott, F. H. (2020). To share or not to share: A social-cognitive internalization model to explain how age discrimination impairs older employees' knowledge sharing with younger colleagues. European Journal of Work and Organizational Psychology, 1-18. https://doi.org/10.1080/1359432X.2020.1839421

Fasbender, U., Wang, M., Voltmer, J.-B., \& Deller, J. (2016). The meaning of work for postretirement employment decisions. Work, Aging and Retirement, 2(1), 12-23. https://doi.org/10.1093/workar/wav015

Fasbender, U., Wöhrmann, A. M., Wang, M., \& Klehe, U. C. (2019). Is the future still open? The mediating role of occupational future time perspective in the effects of career adaptability and aging experience on late career planning. Journal of Vocational Behavior, 111, 24-38. https://doi.org/10.1016/j.jvb.2018.10.006

Fitzpatrick, J., Gareau, A., Lafontaine, M.-F., \& Gaudreau, P. (2016). How to use the ActorPartner Interdependence Model (APIM) to estimate different dyadic patterns in MPlus: A step-by-step tutorial. Quantitative Methods for Psychology, 12, 74-86. https://doi.org/10.20982/tqmp.12.1.p074

Gagné, M. (2009). A model of knowledge-sharing motivation. Human Resource Management, 48, 571-589. https://doi.org/10.1002/hrm.20298

Gagné, M., Tian, A. W., Soo, C., Zhang, B., Ho, K. S. B., \& Hosszu, K. (2019). Different motivations for knowledge sharing and hiding: The role of motivating work design. Journal of Organizational Behavior, 40, 783-799. https://doi.org/10.1002/job.2364

Gerpott, F. H., \& Fasbender, U. (2020). Intergenerational learning in age-diverse meetings: A social comparison perspective. In A. Meinecke, J. Allen, \& N. Lehmann-Willenbrock (Eds.), Managing Meetings in Organizations (Vol. 20, pp. 185-206). Emerald.

Gerpott, F. H., Fasbender, U., \& Burmeister, A. (2020). Respectful leadership and followers' knowledge sharing: A social mindfulness lens. Human Relations, 73(6), 789-810. https://doi.org/10.1177/0018726719844813

Gerpott, F. H., Lehmann-Willenbrock, N., \& Scheibe, S. (2020). Is work and aging research a 
science of questionnaires? Moving the field forward by considering perceived versus actual behaviors. Work, Aging and Retirement, 6, 65-70. https://doi.org/10.1093/workar/waaa002

Gerpott, F. H., Lehmann-Willenbrock, N., \& Voelpel, S. C. (2017). A phase model of intergenerational learning in organizations. Academy of Management Learning and Education, 16, 193-216. https://doi.org/10.5465/amle.2015.0185

Gerpott, F. H., Lehmann-Willenbrock, N., Wenzel, R., \& Voelpel, S. C. (2019). Age diversity and learning outcomes in organizational training groups: the role of knowledge sharing and psychological safety. The International Journal of Human Resource Management, 1-28. https://doi.org/10.1080/09585192.2019.1640763

Grand, J. A., Braun, M. T., Kuljanin, G., Kozlowski, S. W. J., \& Chao, G. T. (2016). The dynamics of team cognition: A process-oriented theory of knowledge emergence in teams. Journal of Applied Psychology, 101(10), 1353-1385. https://doi.org/10.1037/ap10000136

Hagood, E. W., \& Gruenewald, T. L. (2018). Positive versus negative priming of older adults' generative value: do negative messages impair memory? Aging and Mental Health, 22(2), 257-260. https://doi.org/10.1080/13607863.2016.1239063

Harvey, J.-F. (2012). Managing organizational memory with intergenerational knowledge transfer. Journal of Knowledge Management, 16(3), 400-417. https://doi.org/http://dx.doi.org/10.1108/13673271211238733

Henry, H., Zacher, H., \& Desmette, D. (2015). Reducing age bias and turnover intentions by enhancing intergenerational contact quality in the workplace: The role of opportunities for generativity and development. Work, Aging and Retirement, 1, 243-253. https://doi.org/10.1093/workar/wav005

Hung, S. Y., Lai, H. M., \& Chang, W. W. (2011). Knowledge-sharing motivations affecting RD employees' acceptance of electronic knowledge repository. Behaviour and Information Technology, 30(2), 213-230. https://doi.org/10.1080/0144929X.2010.545146

Inceoglu, I., Segers, J., \& Bartram, D. (2012). Age-related differences in work motivation. Journal of Occupational and Organizational Psychology, 85(2), 300-329. https://doi.org/10.1111/j.2044-8325.2011.02035.x

Ipe, M. (2003). Knowledge sharing in organizations: A conceptual framework. Human Resource Development Review, 2, 337-359. https://doi.org/10.1177/1534484303257985

Jiang, Z., Di Milia, L., Jiang, Y., \& Jiang, X. (2020). Thriving at work: A mentoringmoderated process linking task identity and autonomy to job satisfaction. Journal of Vocational Behavior, 118(December 2019), 103373. https://doi.org/10.1016/j.jvb.2019.103373

Kankanhalli, A., Tan, B. C. Y., \& Wei, K. K. (2005). Contributing knowledge to electronic knowledge repositories: An empirical investigation. MIS Quarterly: Management Information Systems, 29(1), 113-143. https://doi.org/10.2307/25148670

Kenny, D. A., Kashy, D. A., \& Cook, W. L. (2006). Dyadic data analysis. Guilford Press.

Klehe, U.-C., Fasbender, U., \& Van der Horst, A. C. (2021). Going full circle: Integrating research on career adaptation and proactivity. Journal of Vocational Behavior.

Kooij, D. T. A. M., De Lange, A. H., Jansen, P. G. W., Kanfer, R., \& Dikkers, J. S. E. (2011). Age and work-related motives: Results of a meta-analysis. Journal of Organizational Behavior, 32(2), 197-225. https://doi.org/10.1002/job.665

Kooij, D. T. A. M., \& Van De Voorde, K. (2011). How changes in subjective general health predict future time perspective, and development and generativity motives over the lifespan. Journal of Occupational and Organizational Psychology, 84, 228-247. https://doi.org/10.1111/j.2044-8325.2010.02012.x

Kuyken, K., Ebrahimi, M., \& \& Saives, A.-L. (2009). Intergenerational knowledge transfer in high-technological companies: A comparative study between Germany and Quebec. The Administrative Sciences Association of Canada (ASAC).

Lawrence, B. S. (1988). New wrinkles in the theory of age: Demography, norms, and performance rating. Academy of Management Journal, 31(2), 309-337. https://doi.org/10.2307/256550

Ledermann, T., Macho, S., \& Kenny, D. A. (2011). Assessing mediation in dyadic data using the actor-partner interdependence model. Structural Equation Modeling, 18(4), 595-612. https://doi.org/10.1080/10705511.2011.607099 
Lee, K.-W. (2019). Learning management knowledge: Integrating learning cycle theory and knowledge types perspective. Academy of Management Learning \& Education. https://doi.org/10.5465/amle.2016.0029

Levallet, N., \& Chan, Y. E. (2019). Organizational knowledge retention and knowledge loss. Journal of Knowledge Management, 23, 176-199. https://doi.org/10.1108/JKM-082017-0358

Liden, R. C., Anand, S., \& Vidyarthi, P. (2016). Dyadic relationships. Annual Review of Organizational Psychology and Organizational Behavior, 3, 139-166. https://doi.org/10.1146/annurev-orgpsych-041015-062452

Lin, H.-F. (2007). Effects of extrinsic and intrinsic motivation on employee knowledge sharing intentions. Journal of Information Science, 33, 135-149. https://doi.org/10.1177/0165551506068174

Massingham, P. R. (2018). Measuring the impact of knowledge loss: a longitudinal study. Journal of Knowledge Management, 22(4), 721-758. https://doi.org/10.1108/JKM-082016-0338

Mor-Barak, M. (1995). The meaning of work for older adults seeking employment: The generativity factor. The International Journal of Aging and Human Development, 41, 325-344.

Muthén, L. K., \& Muthén, B. O. (2019). Mplus user's guide (8th ed.). Muthén \& Muthén.

$\mathrm{Ng}, \mathrm{K}$. Y. N. (2020). The moderating role of trust and the theory of reasoned action. Journal of Knowledge Management, 24(6), 1221-1240. https://doi.org/10.1108/JKM-01-20200071

Nguyen, T. M., Nham, T. P., Froese, F. J., \& Malik, A. (2019). Motivation and knowledge sharing: a meta-analysis of main and moderating effects. Journal of Knowledge Management, 23(5), 998-1016. https://doi.org/10.1108/JKM-01-2019-0029

Pee, L. G., \& Lee, J. (2015). Intrinsically motivating employees' online knowledge sharing: Understanding the effects of job design. International Journal of Information Management, 35(6), 679-690. https://doi.org/10.1016/j.ijinfomgt.2015.08.002

Podsakoff, P. M., MacKenzie, S. B., \& Podsakoff, N. P. (2012). Sources of method bias in social science research and recommendations on how to control it. Annual Review of Psychology, 63, 539-569. https://doi.org/10.1146/annurev-psych-120710-100452

Pratt, M. W., \& Lawford, H. L. (2014). Early generativity and types of civic engagement in adolescence and emerging adulthood. In L. M. Padilla-Walker \& G. Carlo (Eds.), Prosocial Development: A Multidimensional Approach (pp. 410-432). Oxford University Press.

Preacher, K. J., \& Hayes, A. F. (2008). Asymptotic and resampling strategies for assessing and comparing indirect effects in multiple mediator models. Behavior Research Methods, 40, 879-891. https://doi.org/10.3758/BRM.40.3.879

Reinholt, M., Pedersen, T., \& Foss, N. J. (2011). Why a central network position isn't enough: The role of motivation and ability for knowledge sharing in employee networks. Academy of Management Journal, 54, 1277-1297. https://doi.org/10.5465/amj.2009.0007

Roberts, Z., Rogers, A., Thomas, C. L., \& Spitzmueller, C. (2018). Effects of proactive personality and conscientiousness on training motivation. International Journal of Training and Development, 22(2), 126-143. https://doi.org/10.1111/ijtd.12122

Rudolph, C. W., Kooij, D. T. A. M., Rauvola, R. S., \& Zacher, H. (2018). Occupational future time perspective: A meta-analysis of antecedents and outcomes. Journal of Organizational Behavior, 39, 229-248. https://doi.org/10.1002/job.2264

Salthouse, T. (2012). Consequences of age-related cognitive declines. Annual Review of Psychology, 63, 201-226. https://doi.org/10.1146/annurev-psych-120710-100328

Sánchez-Polo, M. T., Cegarra-Navarro, J. G., Cillo, V., \& Wensley, A. (2019). Overcoming knowledge barriers to health care through continuous learning. Journal of Knowledge Management, 23(3), 508-526. https://doi.org/10.1108/JKM-10-2018-0636

Schepers, P., \& Van Den Berg, P. T. (2007). Social factors of work-environment creativity. Journal of Business and Psychology, 21(3), 407-428. https://doi.org/10.1007/s10869006-9035-4

Schmidt, X., \& Muehlfeld, K. (2017). What's so special about intergenerational knowledge transfer? Identifying challenges of intergenerational knowledge transfer. Management Revue, 28, 375-411. https://doi.org/10.5771/0935-9915-2017-4-375 
Shannon, C. E., \& Weaver, W. (1949). The mathematical theory of communication. University of Illinois Press.

Shujahat, M., Wang, M., Ali, M., Bibi, A., Razzaq, S., \& Durst, S. (2020). Idiosyncratic jobdesign practices for cultivating personal knowledge management among knowledge workers in organizations. Journal of Knowledge Management. https://doi.org/10.1108/JKM-03-2020-0232

Siemsen, E., Roth, A. V., \& Balasubramanian, S. (2008). How motivation, opportunity, and ability drive knowledge sharing: The constraining-factor model. Journal of Operations Management, 26(3), 426-445. https://doi.org/10.1016/j.jom.2007.09.001

Siemsen, E., Roth, A. V., Balasubramanian, S., \& Anand, G. (2009). The influence of psychological safety and confidence in knowledge on employee knowledge sharing. Manufacturing and Service Operations Management, 11(3), 429-447. https://doi.org/10.1287/msom.1080.0233

Spector, P. E., \& Brannick, M. T. (2011). Methodological urban legends: The misuse of statistical control variables. Organizational Research Methods, 14, 287-305. https://doi.org/10.1177/1094428110369842

Spitzmuller, M., Sin, H. P., Howe, M., \& Fatimah, S. (2015). Investigating the uniqueness and usefulness of proactive personality in organizational research: A meta-analytic review. Human Performance, 28(4), 351-379.

https://doi.org/10.1080/08959285.2015.1021041

Tempest, S. (2003). Intergenerational learning: A reciprocal knowledge development process that challenges the language of learning. Management Learning, 34, 181-200.

Tornau, K., \& Frese, M. (2013). Construct clean-up in proactivity research: A meta-analysis on the nomological net of work-related proactivity concepts and their incremental validities. Applied Psychology, 62(1), 44-96. https://doi.org/10.1111/j.14640597.2012.00514.x

Truxillo, D. M., Cadiz, D. M., Rineer, J. R., Zaniboni, S., \& Fraccaroli, F. (2012). A lifespan perspective on job design: Fitting the job and the worker to promote job satisfaction, engagement, and performance. Organizational Psychology Review, 2, 340-360. https://doi.org/10.1177/2041386612454043

Voelpel, S., Sauer, A., \& Biemann, T. (2012). Career planning for mid- and late-career workers. In W. C. Borman \& J. W. Hedge (Eds.), The Oxford Handbook of Work and Aging. Oxford University Press.

Wang, M., Beal, D. J., Chan, D., Newman, D. A., Vancouver, J. B., \& Vandenberg, R. J. (2017). Longitudinal research: A panel discussion on conceptual issues, research design, and statistical techniques. Work, Aging and Retirement, 3, 1-24. https://doi.org/10.1093/workar/waw033

Wang, S., \& Noe, R. A. (2010). Knowledge sharing: A review and directions for future research. Human Resource Management Review, 20, 115-131. https://doi.org/10.1016/j.hrmr.2009.10.001

Wheeler, A. R., Shanine, K. K., Leon, M. R., \& Whitman, M. V. (2014). Student-recruited samples in organizational research: A review, analysis, and guidelines for future research. Journal of Occupational and Organizational Psychology, 87(1), 1-26. https://doi.org/10.1111/joop.12042

Wikström, E., Eriksson, E., Karamehmedovic, L., \& Liff, R. (2018). Knowledge retention and age management - senior employees' experiences in a Swedish multinational company. Journal of Knowledge Management, 22(7), 1510-1526. https://doi.org/10.1108/JKM-092017-0442

Wilkesmann, U., Wilkesmann, M., \& Virgillito, A. (2009). The absence of cooperation is not necessarily defection: Structural and motivational constraints of knowledge transfer in a social dilemma situation. Organization Studies, 30, 1141-1164. https://doi.org/10.1177/0170840609344385

Zacher, H., Rosing, K., Henning, T., \& Frese, M. (2011). Establishing the next generation at work: Leader generativity as a moderator of the relationships between leader age, leadermember exchange, and leadership success. Psychology and Aging, 26, 241-252. https://doi.org/10.1037/a0021429

Zacher, H., Schmitt, A., \& Gielnik, M. M. (2012). Stepping into my shoes: Generativity as a mediator of the relationship between business owners' age and family succession. Ageing and Society, 32, 673-696. https://doi.org/10.1017/S0144686X11000547 


\section{Table 1}

Results of Multilevel Confirmatory Factor Analyses (MCFA)

\begin{tabular}{|c|c|c|c|c|c|c|c|c|c|}
\hline \multirow[t]{2}{*}{ Model } & \multicolumn{6}{|c|}{ Model fit } & \multicolumn{3}{|c|}{ Model comparison } \\
\hline & Chi-square & $d f$ & RMSEA & CFI & TLI & SRMR & $\begin{array}{l}\text { Chi-square } \\
\text { difference }\end{array}$ & $\Delta \mathrm{df}$ & p-value \\
\hline Four-factor model ${ }^{\mathrm{a}}$ & 131.299 & 59 & .065 & .957 & .943 & .048 & $\mathrm{~N} / \mathrm{A}$ & N/A & N/A \\
\hline Three-factor model ${ }^{\mathrm{b}}$ & 356.071 & 62 & .128 & .824 & .778 & .083 & 224.772 & 3 & $<.001$ \\
\hline Three-factor model ${ }^{\mathrm{c}}$ & 390.987 & 62 & .135 & .803 & .752 & .119 & 259.688 & 3 & $<.001$ \\
\hline Two-factor model ${ }^{\mathrm{d}}$ & 585.496 & 64 & .168 & .688 & .619 & .131 & 454.197 & 5 & $<.001$ \\
\hline One-factor model ${ }^{\mathrm{e}}$ & 1040.424 & 66 & .226 & .416 & .310 & .176 & 909.125 & 7 & $<.001$ \\
\hline \multicolumn{10}{|c|}{ Note. $N=145$ dyads (290 individuals). RMSEA = root-mean-square error of approximation; $\mathrm{CFI}=$ comparative fit index; TLI $=$ Tucker-Lewi } \\
\hline
\end{tabular}




\section{Table 2}

Means, Standard Deviations, and Correlations of Variables

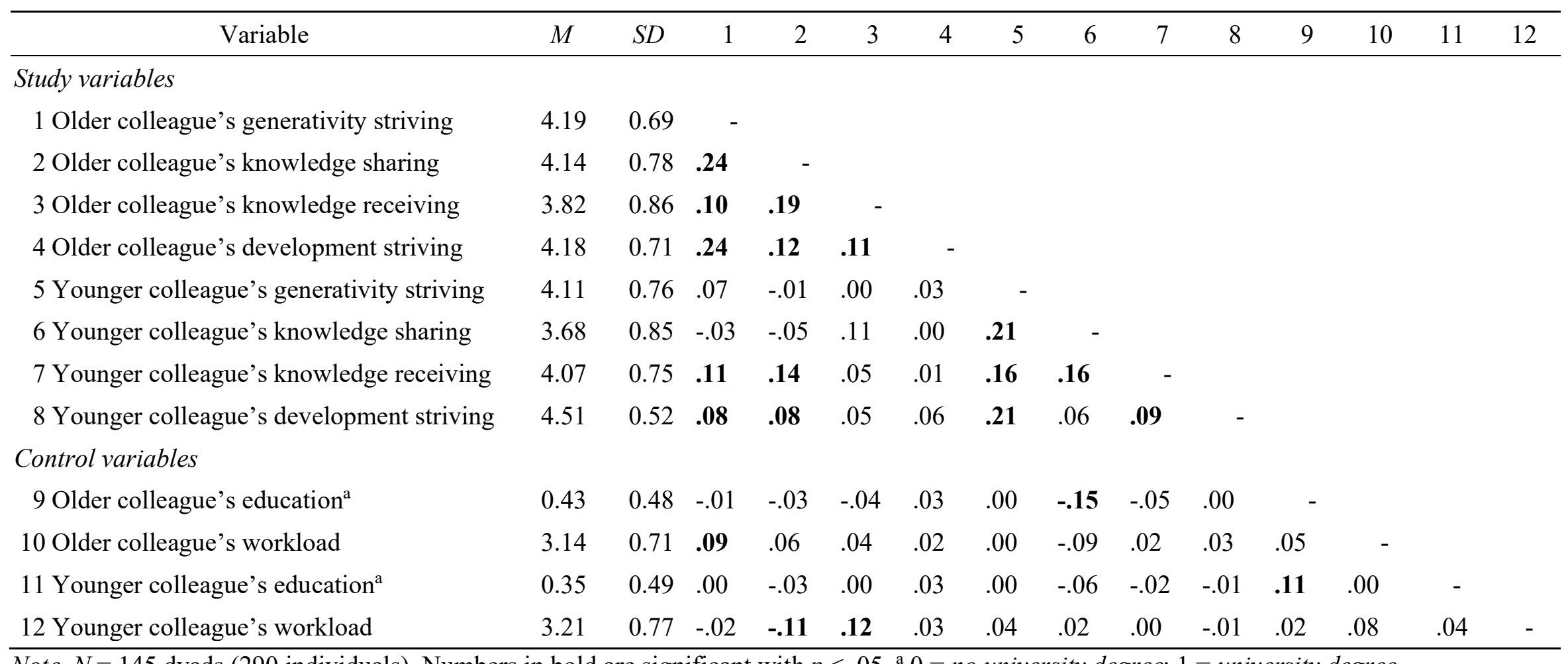

Note. $N=145$ dyads (290 individuals). Numbers in bold are significant with $p<.05 .{ }^{\mathrm{a}} 0=$ no university degree; $1=$ university degree. 


\section{Table 3}

Results of Actor-Partner Interdependence Modelling

\begin{tabular}{|c|c|c|c|c|c|c|}
\hline Direct effects & \multicolumn{3}{|c|}{ Older colleague's knowledge sharing } & \multicolumn{3}{|c|}{ Younger colleague's knowledge sharing } \\
\hline Generativity striving (self) & .506 & .085 & $<.001$ & .379 & .089 & $<.001$ \\
\hline \multirow[t]{2}{*}{ Generativity striving (other) } & -.068 & .077 & .377 & -.114 & .098 & .244 \\
\hline & \multicolumn{3}{|c|}{ Younger colleague's knowledge receiving } & \multicolumn{3}{|c|}{ Older colleague's knowledge receiving } \\
\hline Knowledge sharing (other) (A) & .230 & .076 & .002 & .165 & .079 & .038 \\
\hline Knowledge sharing (self) & .229 & .067 & .001 & .272 & .091 & .003 \\
\hline Development striving (self) (B) & .290 & .116 & .012 & .137 & .097 & .156 \\
\hline Development striving (other) & -.080 & .082 & .331 & .061 & .134 & .648 \\
\hline
\end{tabular}

Note. $N=145$ dyads (290 individuals). Direct and indirect effects of generativity striving, knowledge sharing, and development striving with bootstrapped-corrected confidence intervals for indirect effects. $S E=$ standard error. $C I L L=$ lower level of $95 \%$ confidence interval, $C I U L=$ upper level of $95 \%$ confidence interval. Significant coefficients are highlighted in bold. 


\section{Table 4}

Conditional Indirect Effects of Generativity on Knowledge Receiving via Knowledge Sharing

\begin{tabular}{|c|c|c|c|c|c|c|}
\hline & \multicolumn{3}{|c|}{ Younger colleague's knowledge receiving } & \multicolumn{3}{|c|}{ Older colleague's' knowledge receiving } \\
\hline & Coefficient & $C I L L$ & $C I U L$ & Coefficient & $C I L L$ & CI UL \\
\hline \multicolumn{7}{|l|}{$\begin{array}{l}\text { Generativity striving (other) via knowledge } \\
\text { sharing (other) at }\end{array}$} \\
\hline Higher development striving (self) (A) & .198 & .083 & .351 & .091 & .019 & .217 \\
\hline Lower development striving (self) (B) & .035 & -.067 & .128 & .034 & -.066 & .128 \\
\hline Difference of (A) and (B) & .163 & .047 & .359 & .058 & -.053 & .218 \\
\hline
\end{tabular}

Note. $N=145$ dyads (290 individuals). $C I L L=$ lower level of bootstrapped-corrected $95 \%$ confidence interval, $C I U L=$ upper level of

bootstrapped-corrected $95 \%$ confidence interval. Significant coefficients are highlighted in bold. 


\section{Table 5}

Recommendations for Future Research

\begin{tabular}{|c|c|}
\hline Concern & Recommendation \\
\hline $\begin{array}{l}\text { Common-method } \\
\text { bias/over-reporting of } \\
\text { socially desirable behavior }\end{array}$ & $\begin{array}{l}\text { Objective measures of knowledge sharing and/or receiving can help to reduce the risk of common-method bias } \\
\text { and over-reporting of their knowledge sharing as a socially desirable behavior, for example: } \\
\text { - Record meetings between age-diverse employees to code verbal expressions of knowledge sharing } \\
\text { - Ask employees to visualize the received knowledge to grasp the actual information obtained }\end{array}$ \\
\hline $\begin{array}{l}\text { Causality between the } \\
\text { investigated relationships }\end{array}$ & $\begin{array}{l}\text { Longitudinal design to derive causal priorities between the investigated relationships, for example: } \\
\text { - Employees' motives, their knowledge sharing, and knowledge receiving responses can be measured at } \\
\text { different points in time } \\
\text { Experimental design/field intervention to allow causal inferences, for example: } \\
\text { - Experimental design: Manipulate the salience of employee's motives (i.e., generativity and development } \\
\text { striving) with the use of priming cues (i.e., provide cues in form of text or picture material that activate } \\
\text { these motives in a person's memory). } \\
\text { - Field intervention: create more opportunities for generativity (e.g., mentoring programs, institutionalized } \\
\text { peer-to-peer learning initiatives) and opportunities for development (e.g., brownbag lunches, challenging } \\
\text { work tasks) in employees' job }\end{array}$ \\
\hline $\begin{array}{l}\text { Different effects of } \\
\text { employees' motives } \\
\text { depending on knowledge } \\
\text { types }\end{array}$ & $\begin{array}{l}\text { Capture different types of knowledge to understand whether employees' motives may have different effects on } \\
\text { knowledge sharing and receiving, for example: } \\
\text { - Use taxonomy of knowledge types that represent varying degrees of knowledge complexity (e.g., know- } \\
\text { what, know-how, know-when, and know-why) }\end{array}$ \\
\hline $\begin{array}{l}\text { Understanding the role of } \\
\text { personality (e.g., proactive } \\
\text { personality) }\end{array}$ & $\begin{array}{l}\text { Account for the role of personality (e.g., proactive personality which is expressed in taking charge or showing } \\
\text { personal initiative) that may shape employees' motives and impact knowledge exchange, for example: } \\
\text { - Use valid (proactive) personality assessment measures (e.g., Bateman \& Crant, 1993; Claes et al., 2005) }\end{array}$ \\
\hline
\end{tabular}




\section{Figure 1}

Actor-Partner Interdependence Model of Knowledge Exchange between Older and Younger Employees

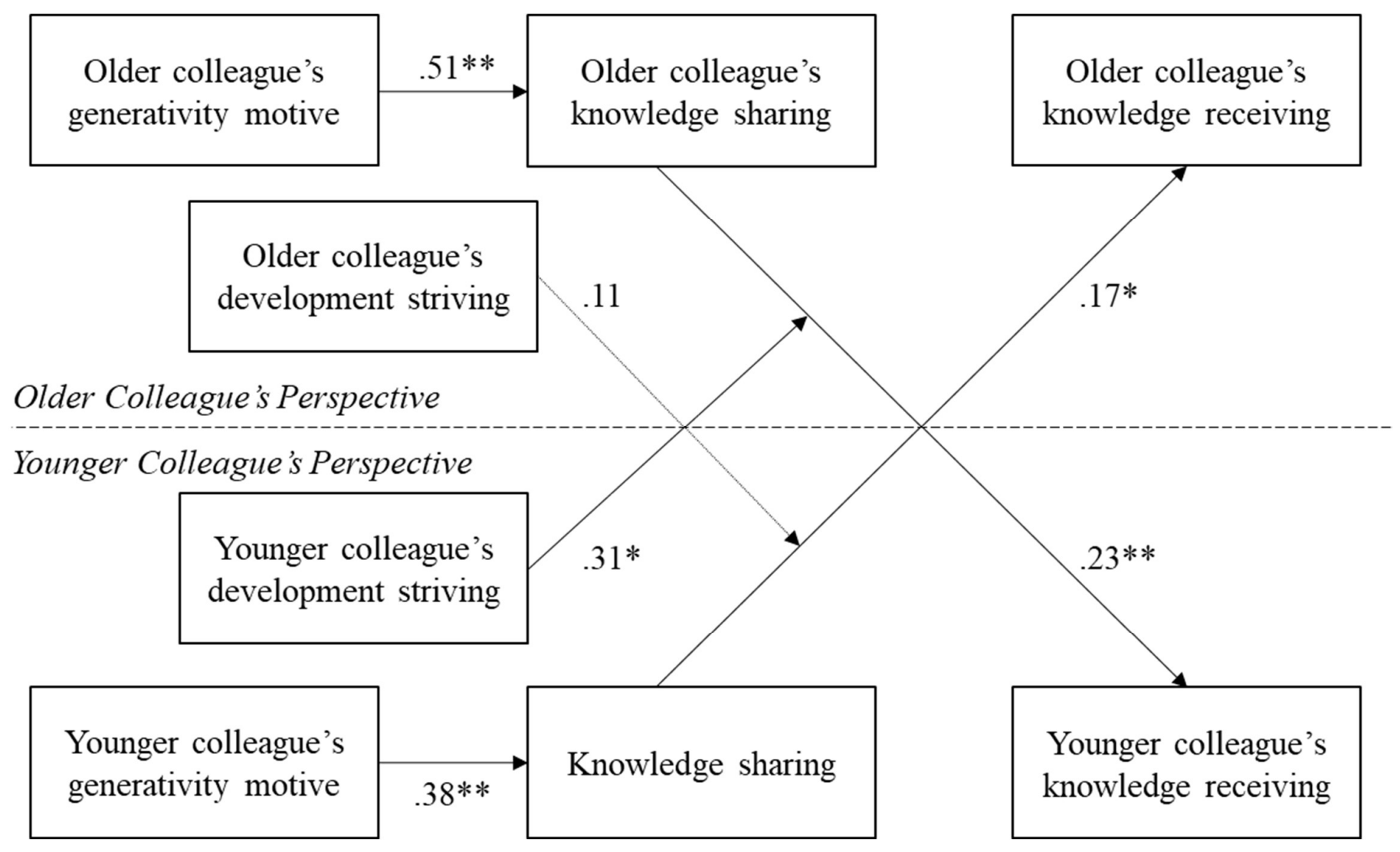

Note. ${ }^{*} p<.05, * * p<.01$. 


\section{Figure 2}

Younger Colleague's Development Striving Moderates the Effect of Older Colleague's Knowledge Sharing on Younger Colleague's Knowledge Receiving






\section{Appendix}

\section{Generativity Striving}

Kooij \& Van De Voorde (2011), five-point scale $(1=$ not important at all, $5=$ very important $)$

English items

How important is...

1. ... the opportunity to share your skills with other people for you?

2. ... the opportunity to pass your knowledge to the next generation for you?

3. ... the chance to teach and train others for you?
Translated German items

Wie wichtig ist Ihnen...

1. ...die Möglichkeit ihre Kompetenzen mit anderen Personen zu teilen?

2. ...die Möglichkeit, Ihr Wissen an die nächste Generation weiterzugeben?

3. ... die Chance zu lehren und andere auszubilden?

\section{Knowledge Sharing}

Wilkesmann et al. (2009), five-point scale ( 1 = strongly disagree, 5 = strongly agree $)$

English items

1. At work...

2. ... I show my colleague special procedures so that he/she can learn them.

3. ... I support my colleague's effort to gain work experience.

4. ... my colleague learns a lot by watching me on the job.
Translated German items

Bei der Arbeit...

1. ... zeige ich meinem Kollegen besondere Vorgehensweisen, sodass er/sie diese lernen kann.

2. ... unterstütze ich die Anstrengungen meines Kollegen, Wissen zu akquirieren.

3. ... ermögliche ich es meinem Kollegen eine Menge zu lernen, indem er/sie mir bei der Arbeit zusehen kann.

\section{Knowledge Receiving}

Wilkesmann et al. (2009), five-point scale ( 1 = strongly disagree, 5 = strongly agree $)$

English items

At work...

1. ... I learn a lot by observing my colleague doing his/her job.

2. ... I turn to my colleague for advice regarding special procedures so that I learn them.

3. ... I make an effort to receive knowledge from my colleague.

4. ... I learn a lot by asking my colleague.
Translated German items

Bei der Arbeit...

1. ...lerne ich viel dadurch, dass ich meinem Kollegen bei der Arbeit zusehe.

2. ... wende ich mich an meinen Kollegen für Ratschläge hinsichtlich besonderer Vorgehensweisen, so dass ich diese lernen kann.

3. ... bemühe ich mich, Wissen von meinem Kollegen aufzunehmen.

4. ... lerne ich viel dadurch, dass ich meinen Kollegen um Rat frage. 


\section{Development Striving}

Kooij \& Van De Voorde (2011), five-point scale $(1=$ not important at all, 5 = very important $)$

English items

How important is...

1. ... the opportunity for personal development for you?

2. ... the opportunity to learn something new for you?

3. ... being able to fully use your skills and abilities for you?
Translated German items

Wie wichtig ist Ihnen...

1. ... die Möglichkeit der persönlichen Weiterentwicklung?

2. ... die Möglichkeit, etwas Neues zu lernen?

3. ... die Möglichkeit, Ihre Fähigkeiten und Kompetenzen voll zu nutzen?

\section{Control Variables: Education}

Binary coded with $0=$ no university degree and $1=$ university degree

English item

1. Please indicate your highest educational degree.
Translated German items

1. Bitte geben Sie Ihren höchsten Bildungsabschluss an.

\section{Control Variable: Workload}

Wu et al. (2014), five-point rating scale ( 1 = strongly disagree, $5=$ strongly agree $)$

English items

1. To what extent does your job require you working fast?

2. To what extent is there not enough time for you to do your job?

3. To what extent do you feel there is not enough time for you to finish your work?
Translated German items

1. In welchem Ausmaß erfordert Ihr Job, dass Sie schnell arbeiten?

2. In welchem Ausmaß haben Sie nicht genug Zeit, um Ihren Job zu erledigen?

3. In welchem Ausmaß haben Sie das Gefühl, dass Sie nicht genug Zeit haben um Ihre Arbeit zu beenden? 